\title{
Sea level extremes at the coasts of China
}

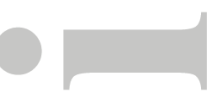

Xianbo Feng ${ }^{1,2,3}$ and Michael N. Tsimplis ${ }^{1,2}$

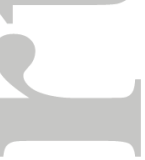

${ }^{1}$ National Oceanography Centre, Southampton, UK

${ }^{2}$ School of Ocean and Earth Science, University of Southampton, UK

${ }^{3}$ State Key Laboratory of Hydrology-Water Resources and Hydraulic

\section{Engineering, Hohai University, Nanjing, China}

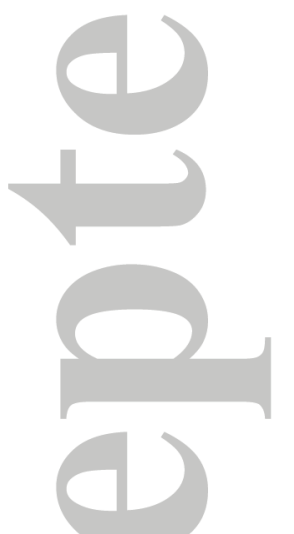

${ }^{*}$ Corresponding author address: National Oceanography Centre, Southampton, European Way, Southampton S014 3ZH, UK

Email: xiangbo.feng@soton.ac.uk

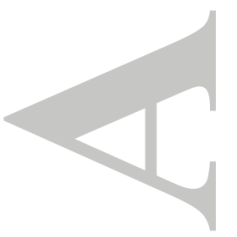

This article has been accepted for publication and undergone full peer review but has not been through the copyediting, typesetting, pagination and proofreading process which may lead to differences between this version and the Version of Record. Please cite this article as doi: 10.1002/2013JC009607 


\section{Abstract}

Hourly sea level records from 1954 to 2012 at twenty tide gauges at and adjacent to the Chinese coasts are used to analyse extremes in sea level and in tidal residual. Tides and tropical cyclones determine the spatial distribution of sea level maxima. Tidal residual maxima are predominantly determined by tropical cyclones. The 50-year return level is found to be sensitive to the number of extreme events used in the estimation. This is caused by the small number of tropical cyclone events happening each year which lead to other local storm events included thus significantly affecting the estimates.

Significant increase in sea level extremes is found with trends in the range between 2.0-14.1 $\mathrm{mm} \mathrm{yr}^{-1}$. The trends are primarily driven by changes in median sea level but also linked with increases in tidal amplitudes at three stations. Tropical cyclones cause significant interannual variations in the extremes. The interannual variability in the sea level extremes is also influenced by the changes in median sea level at the north and by the 18.6-year nodal cycle at the South China Sea. Neither of PDO and ENSO is found to be an indicator of changes in the size of extremes, but ENSO appears to regulate the number of tropical cyclones that reach the Chinese coasts.

Global mean atmospheric temperature appears to be a good descriptor of the interannual variability of tidal residual extremes induced by tropical cyclones but the trend in global temperature is inconsistent with the lack of trend in the residuals. 


\section{Introduction}

The rapid economic progress of China is reflected in the development of significant infrastructure at the coastal zone. The expansion of ports and coastal facilities and the increase in coastal population are accompanied by increased concern with regards to exposure to the catastrophic effects of sea level extremes. In 1997, typhoon Winnie causing US\$ 3 billion of economic loss and several hundred deaths, primarily due to flooding to Taiwan and mainland China [Mackey and Krishnamurti, 2001]. For 2012 the Chinese national authorities indicated that US\$ 2 billion of economic loss and 9 lives were the result of several large storm surge events [SOA, 2013a]. Additional impacts are caused by salty water intrusions [Cartwright and Nielsen, 2004; Zhang et al., 2009], morphological changes [Yang et al., 2003; Fan et al., 2006; Zhou et al., 2013], increased coastline erosion [Cai et al., 2009] and ecosystem changes [Fan and Li, 2006]. Hallegatte et al. [2013] classify the Chinese coast as one of the most vulnerable areas under climate change scenarios. Improved understanding of sea level extremes at the Chinese coasts is essential for development planning, coastal protection and conservation of coastal and marine ecosystems.

Leaving tsunamis aside, storm surges combined with tides are by far the more important forcing parameters for the generation of sea level extremes. Studies on sea level both globally and regionally identify changes in extremes consistent with changes in mean sea level [Woodworth and Blackman, 2004, Marcos et al., 2009; Haigh et al., 2010; Menéndez and Woodworth, 2010; Tsimplis and Shaw, 2010]. 
Climate change scenarios suggest sea level rise in many parts of the world and also the possibility of changes in storminess. The latter are still debatable [see Trenberth and Fassulo, 2007; Trenberth et al., 2007; Knutson et al., 2010; Murakami et al., 2012 and references therein], but if they happen they could lead to changes in the extremes, in addition to those caused by the mean sea level rise, thus exacerbating the risks involved.

For the Chinese coasts mean sea level changes, since 1950, have been reported to be in the range 1.4-2.9 $\mathrm{mm} \mathrm{yr}^{-1}$ [Yanagi and Akaki, 1994; Ding et al., 2001; Lau, 2006; Doong et al., 2009; Marcos et al., 2012; SOA, 2013b].

Tropical cyclones cause the largest storm surges at the Chinese coasts of the Northwestern (NW) Pacific. The highest surge measured by $\sim 6 \mathrm{~m}$ was associated with the landfalling of a tropical cyclone and located at an estuary of China [Yin et al., 2009]. Future projections based on theory and high-resolution dynamical models indicate a shift towards stronger storms, with intensity increases of 2$11 \%$ by 2100 , under greenhouse warming [Knutson et al., 2010]. A complicated picture regarding the frequency of tropical cyclones emerges from modeling studies which consists of an overall reduction of the frequency of tropical cyclones but with an increases in the frequency of the most intense of them [Knutson et al., 2010]. In addition, significant differences between models exist. A number of studies [Emanuel, 2005; Webster et al., 2005, 2006; Kuleshov et al., 2008] have claimed significant increases in extreme tropical cyclone activity, in terms of occurrence, intensity and lifetime, since the 1970s and have linked them with changes in sea surface temperature. However the significance of such trends has been disputed due to the heterogeneity of the available tropical 
cyclone data and the associated inherent trends [Landsea et al., 2006], and the large interdecadal variability in tropical cyclone activity [Chan, 2006]. Kuleshov et al. [2010] do not find statistically significant trends in the Southern Hemisphere with improved datasets.

The interannual variations of tropical cyclones have been linked with EI NiñoSouthern Oscillation (ENSO) with strong activities observed during EI Niño and weak activities during La Niña and with shifts in the tropical cyclone tracks caused by the oscillation [Gray, 1984; Lander, 1994; Kuleshov and de Hoedt, 2003; Chan and Liu, 2004; Kuleshov et al., 2008]. In the northwestern Pacific, the response of tropical cyclone on different phases of ENSO can be interpreted by the sea surface temperature anomaly in the central Pacific [Kim et al., 2011] and by the change of westerly wind shear from the tropical Indian Ocean [ $\mathrm{Du}$ et al., 2011].

Changes in the tidal signal may also be important. Apart from the effects of the nodal cycle on tidal amplitudes [Pugh, 1996; Gratiot, et al., 2008], changes in the amplitudes of some diurnal and semi-diurnal tidal constituents have also been identified and speculated as changes in the propagation of the tidal signal due to the changes in bathymetry associated with mean sea level changing [Egbert et al., 2004; Jay, 2009; Green, 2010; Müller et al., 2011; Pickering et al., 2012]. The significant land reclamation that takes place at the Chinese coasts and involves thousands of square km [Li et al., 2004; Wang et al., 2011] has been suggested to increase the tidal influence on storm surges [Song et al., 2013]. 
Despite the importance of sea level extremes for the coastal areas of China there are, to our knowledge, no published studies concerned with mapping the extremes in the area and resolving their temporal changes.

This paper provides an analysis of extremes in sea level derived from hourly observations at 20 tide gauges at and adjacent to the Chinese coasts. The contribution of tropical cyclones to the observed extreme distribution is resolved by analysing the extremes with and without the influence of tropical cyclones.

The data and methodology are described by section 2 , along with the definitions of extremes used. Section 3 examines the spatial distributions of extremes in terms of maximum events and return levels. In section 4, the trends in sea level extremes and their association with changes in mean sea level and tidal signal are first evaluated. The interannual variability of extremes is also investigated. Conclusions are given in section 5.

\section{Data and Methodology}

\subsection{Sea level data}

Hourly sea level data from tide gauges at the Chinese coasts were obtained from the University of Hawaii Sea Level Center. Data from three stations at the Japanese Ryukyu islands and one in Vietnam are also included in the study. The sea level records span different periods between 1954-2012. The locations of tide gauges and the periods of observations are shown in Figure 1. Twenty records were selected, 17 of which are longer than 23 years. 
The quality control included visual checks of the hourly values month by month of both the original measurements and the tidal residuals. Values with spurious jumps, datum shifts and time shifts were removed. In addition, three years at Keelung and one year at Naha when the data are less than $60 \%$ complete were excluded from the temporal analysis, but they were still kept in the return level analysis to ensure all observed extreme events considered.

At Hong Kong sea level was recorded at North Point station between 1962-1986 and then moved half a kilometer to Quarry Bay station. The two stations used the same measurement instrument and referred to the same datum [Ding et al., 2001]. The offset between the two records is $1.02 \mathrm{~cm}$. After shifting the data by $1.02 \mathrm{~cm}$ a combined 51-year record was created. Thus 19 records were analysed. After the quality control, the mean of each sea level record over the whole observational period was removed. Then the tidal constituents were estimated year by year by using the sea level processing package SLPR2 version 3.0 (http://ilikai.soest.hawaii.edu). The tidal analysis did not include the annual and semi-annual components, as these are primarily not astronomic in characters [Torres and Tsimplis, 2012]. A tidal prediction based on the estimated tidal constituents was then produced and subtracted from the observed sea level, thus creating tidal residual for each record. The 10 largest events in terms of sea level and tidal residual for each year were selected. The analysis was also performed with 7, 5, 3 and 1 extreme events per year. Fewer extreme events per year reduce the capability of extreme statistics to describe the tail of the sea level or tidal residual distribution accurately enough. When more events are used these may include non-extreme values in the analysis. By comparing the outcome of 
the analysis when using different number of extremes we assess the sensitivity of our estimates. To ensure independence between extreme events it was required that they were at least 120 hours apart. This choice is justified in next subsection.

One comparison of the relative importance of the atmospheric forcing is the ratio of variance of the tidal residual over the variance of the observations. This is shown in Figure 2a. The tidal residual accounts for less than $22 \%$ in all stations. The maximum value is found at Keelung of Taiwan. When the same ratio is calculated only for the periods over which tropical cyclones affect sea level, the ratio increases at all stations, but the spatial pattern remains the same. The increase ranges between 1.2 and 2.1 times the ratio calculated for the observations. Note though that the spatial distribution of the standard deviation for the tidal residuals (Figure 2b) show that the largest values are found at the northernmost stations, where their significance in terms of ratio of variance is reduced due to the large tidal signal.

\subsection{Historic tropical cyclones}

Information on tropical cyclones was obtained from the Regional Specialized Meteorological Center Tokyo of Japan Meteorological Agency (RSMC Tokyo of JMA). Tropical storms with a maximum sustained wind speed in excess of 34 knots are classified as tropical cyclones, according to World Meteorological Organization. Six hourly values for the centre position, the central pressure, the maximum sustained wind speed and the radius of area with maximum sustained wind speed over 50 knots for tropical cyclone were obtained. For the period 
analysed here (1954-2012), 1619 tropical cyclones were identified in the area of interest.

Frank [1977] found, on the basis of 10 years of observations from tropical cyclones in the area, that the surface wind induced by cyclones could extend up to $\sim 8^{\circ}$ from the center. For each tropical cyclone we defined the area of its influence on sea level as a circle around the low-pressure center with $10^{\circ}$ radius.

Sea level data within the area of influence of tropical cyclones (TC) will be called TC-influenced sea level or TC-influenced tidal residual. Sea level records here were found to be influenced by each tropical cyclone on average for about 80 hours. Thus, it was required that successive extreme events were separated by 120 hours to ensure they were independent of each other.

\subsection{Generalized Pareto Distribution and percentile}

The return values for sea level extremes were estimated by the Generalized Pareto Distribution (GPD), which has been widely used in estimating the probability of extremes [Smith, 1989; Palutikof et al., 1999; Coles, 2001; Marcos et al., 2009].

Assuming the annual large enough values $\eta$ in successive years are independent and identically distributed values, the GPD can be estimated by a reformulation of the family of extreme value distribution, and the corresponding cumulative distribution is given by Coles [2001] 
$F\left(\eta^{\prime} \mid k, \sigma\right)=\left\{\begin{array}{c}1-\left(1+k \frac{\eta^{\prime}}{\sigma}\right)^{-1 / k}, k \neq 0 \\ 1-\exp \left(-\frac{\eta^{\prime}}{\sigma}\right)^{-1 / k}, k=0\end{array}\right.$

where $\eta^{\prime}=\eta-\mu$ defined as the excesses of $\eta$ over threshold $\mu, \sigma$ is a scale parameter and $k$ a shape parameter. When $k<0, k=0$ and $k>0$, the distribution is known as Weibull, Gumbel and Fréchet distributions respectively.

The return period is an estimate of occurrence interval for the likelihood of an extreme event, and the $\mathrm{N}$-year return level is the level that is expected to be equaled or exceeded once for a given distribution by the annual maxima in $\mathrm{N}$ years with probability $1-F=1 / \mathrm{N}$. Thus, the $\mathrm{N}$-year return level of extreme event in Eq. (1), $Z_{p}$, is given by Eq. (2)

$Z_{p}=\left\{\begin{array}{l}\mu+\frac{\sigma}{k}\left(N^{k}-1\right), k \neq 0 \\ \mu+\sigma \ln (N), k=0\end{array}\right.$

After the scale and shape parameters of $\sigma$ and $k$ were estimated by fitting Eq.

(1) to the annual extremes using the maximum likelihood method, the N-year return level could be calculated then by Eq. (2).

Here we fit the GPD to the $m$-largest annual events. This means that the threshold $\mu$ in Eq. (1) corresponds to the $(m+1)^{\text {th }}$ largest event in each year. A value of $m=5$ in GPD was recommended in the Mediterranean Sea, based on a generalized extreme value distribution [Tsimplis and Blackman, 1997; Marcos et al., 2009]. We experimented fitting the GPD to $m=1,3,5,7$ and 10 largest annual values. This enables us to detect the sensitivity of return levels to $m$. 
We used percentile analysis to assess temporal changes of extremes. In a nonleap year, there are 8760 hourly values of sea level (and tidal residual) measurements. They were sorted into an ascending order, and the levels at each percentile were then estimated. Changes in the $99.9^{\text {th }}$ percentile were used to represent the changes in extremes. This corresponds to the $8^{\text {th }}$ highest annual value. The $50^{\text {th }}$ percentile was also estimated. We further computed the $99.9^{\text {th }}$ and $50^{\text {th }}$ percentiles of sea level and tidal residual when the TC-influenced events were not included in order to assess the importance of tropical cyclones for each tide gauge studied.

The percentile analysis was restricted to tide-gauge stations with 19 or more years of observations in order to reduce the effect of the 18.6 year nodal modulation [Pugh, 1996; Gratiot, et al., 2008; Haigh et al., 2010; Shaw and Tsimplis, 2010; Torres and Tsimplis, 2011].

Note that the statistical significance of the correlation coefficient and the linear trend is assessed at the $95 \%$ confidence level.

\section{Spatial distribution of observed extremes}

\subsection{Maximum values}

Over the whole period of observation, the maxima in sea level ranged between $402-460 \mathrm{~cm}$ at the East China Sea coasts, 246-354 $\mathrm{cm}$ at the Bohai Sea and

Yellow Sea coasts, and $157-336 \mathrm{~cm}$ at the South China Sea coasts (Figure 3a). The maxima of sea level at the island sites were lower and ranged between 108-174 $\mathrm{cm}$. The highest extreme was observed at Kanmen $(460 \mathrm{~cm})$, and the smallest at 
Kaohsiung $(108 \mathrm{~cm})$. The correlation coefficient between the maxima in sea level at each tide gauge and the sum of the largest diurnal and semidiurnal constitutes $\mathrm{M}_{2}+\mathrm{K}_{1}$ is statistically significant and has a value of 0.97 , indicating the important role that the tidal signal plays in determining the extreme values observed.

The maxima in the tidal residual were between $56-200 \mathrm{~cm}$ (Figure 3b), being 113-200 cm at the East China Sea, the Yellow Sea and the northern South China Sea. At the Bohai Sea and western South China Sea, the values of maxima were decreased to $91-124 \mathrm{~cm}$, while at the islands the range was even lower, between $68-106 \mathrm{~cm}$. The highest and lowest maxima in the tidal residual were found at Lusi $(200 \mathrm{~cm})$ and Quinohn $(56 \mathrm{~cm})$ respectively. The correlation between the maxima in tidal residual and the sum of $\mathrm{M}_{2}+\mathrm{K}_{1}$ tidal components is reduced to 0.67 but is statistically significant. The possibility of tide-surge interaction will be discussed later.

The maxima in sea level occurred during the passing of tropical cyclones at all stations but three, namely Dongfang, Quinohn and Lusi. Dongfang and Quinohn are at latitudes less than $20^{\circ} \mathrm{N}$ where the tropical cyclone frequency is low (this will be shown later). Lusi is the third exception where the tidal amplitude is large. The maxima in sea level when the TC-influenced sea level values are omitted can be seen in Figure 3c. They ranged between $80-424 \mathrm{~cm}$. The differences in the size of the maxima between Figure $3 \mathrm{a}$ and Figure 3c demonstrate the importance of tropical cyclones for this area. The average of the difference between maxima sea level estimated from the observations and when the TC-influence values omitted, that is the difference between the values of 
Figure $3 \mathrm{a}$ and Figure $3 \mathrm{c}$, is $32 \pm 13 \mathrm{~cm}$. This indicates that the change is statistically significant.

All of the maximum values in tidal residual occurred during tropical cyclones, except at the most southern station of Quinohn. The range of maxima in the absence of tropical cyclones was 39-146 cm (Figure 3d), overall 58 $\pm 15 \mathrm{~cm}$ lower than the values when TC events are involved. Relatively higher values were again found at the mainland coasts of the Yellow Sea and the East China Sea, and lower values at the island coasts. The spatial values are more coherent when TC events are excluded.

The importance of tropical cyclones for extremes in this area can also be demonstrated by looking at the top 10 events at each tide gauge and identify how many are TC-influenced. This is shown in Figure 4a. The influence of tropical cyclones is dominant for the stations between Lianyungang and Haiku both for observed sea level and tidal residual. The dominance of tropical cyclones for tidal residual is more extensive and covers the area from Shijiusuo to Beihai.

In Figure $4 \mathrm{~b}$ TC-influenced events per year for each station is shown. Fewer tropical cyclones affect sea level at the north part of the area of study while more than 10 in the area between $20^{\circ}-30^{\circ} \mathrm{N}$. The most affected area is that around Taiwan.

Two of the top 5 sea level events at the Yellow Sea and the East China Sea were caused by two of the deadliest and most destructive tropical cyclones ever recorded in the NW Pacific [Mackey and Krishnamurti, 2001; Wu et al., 2002; 
Moon et al., 2003], Herb 25 $5^{\text {th }}$ July-3 ${ }^{\text {rd }}$ August 1996 and Winnie $10^{\text {th }}-20^{\text {th }}$ August 1997.

In summary, sea level extremes in the area are due to the combination of tides and tropical cyclones. By contrast extremes in tidal residual at most stations are exclusively linked with tropical cyclones. This has two consequences. First, statistical analysis of extremes, e.g. extremes at certain return levels, is possible as the extremes are predominantly linked with the same population of tropical cyclones. The downside is that any projection in the future would require some knowledge of the changes in the strength and path of tropical cyclones, arguably beyond the skill of existing climate change models.

\subsection{0-year return levels}

The 50-year return levels of sea level and the tidal residual estimated from the 5 largest events each year are shown by the black lines in Figure $5 \mathrm{a}$ and $5 \mathrm{~b}$. As expected the return levels have the same pattern as the maxima observed. The return levels of sea level and residual are reduced by $\sim 28 \mathrm{~cm}$ and $\sim 76 \mathrm{~cm}$ respectively when the effects of tropical cyclones are not taken into account (Figure $5 \mathrm{c}$ and $5 \mathrm{~d}$ ).

The 50-year return levels estimated for different number of largest events per year $(m=1,3,5,7$ and 10$)$ are also shown in Figure 5. For sea level, the average difference between highest and lowest values for 50 -year return level is $17 \mathrm{~cm}$.

The biggest discrepancy occurs at Haikou where the 50-year return level with $m=1$ is $70 \mathrm{~cm}$ higher than that with $m=7$. The return level with $m=1$ is $59 \mathrm{~cm}$ higher than that with $m=10$ at Kanmen. At other sites, the differences are in the range of $2-37 \mathrm{~cm}$. 
For tidal residuals, the average of discrepancy between highest and lowest values is $41 \mathrm{~cm}$. The biggest discrepancy is found at Laohutan where the return level with $m=3$ is $119 \mathrm{~cm}$ higher than that with $m=10$, followed by Beihai and Kanmen, with $113 \mathrm{~cm}$ and $102 \mathrm{~cm}$ respectively. The estimates for these sites are very sensitive to the number of largest events. For other sites, the uncertainties are smaller but not negligible in the range of $2-70 \mathrm{~cm}$.

When the TC-influenced sea level is excluded, the difference in the 50-year return levels for the values of $m$ used is reduced to $\sim 4 \mathrm{~cm}$ on average for both sea level and tidal residual (Figure $5 c$ and $5 d$ ). Thus the estimation of the GPD is very sensitive to the annual number of extremes taken into account and this sensitivity is only due to variability in the TC-influenced extremes.

\subsection{Tide-surge interaction}

Nonlinear tide-surge interaction can be an important factor during extreme events. For the East China Sea, Zhang et al. [2010] indicated that the difference of tidal residuals due to the interaction could reach up to $20 \mathrm{~cm}$. We use the highest 5 events per year in tidal residual to assess the tide-surge interaction. If the tidesurge interaction is insignificant, the extreme events in tidal residual should be distributed uniformly with the phase of the tide. In order to determine whether the interaction is statistically significant, the $\chi^{2}$ test is used to evaluate the difference of the event distribution from the uniform distribution (Table 1). We find that tide-surge interaction is significant at 15 out of 19 sites. At Shijiusuo, Lianyungang, Lusi and Xiamen, the extreme values in tidal residual occur more frequently in the time of rising tide. At Zhapo and Quinohn, more extremes are distributed in the time of falling tide. We have also repeated the same analysis 
after omitting the TC-influenced data. The results do not change substantially and the tide-surge interaction is still significant at 15 stations, except that the interaction becomes significant at Naha and becomes insignificant at Keelung (Table 1$)$.

\section{Temporal changes of extremes}

\subsection{Trends}

The temporal changes of observed extremes are analysed at 17 tide gauges that have records longer than 18 years. The values of the $99.9^{\text {th }}$ percentile of sea level are shown in Figure 6. All stations show positive trends that are statistically significant at 12 stations (Table 2). The trend values range between $2.0 \mathrm{~mm} \mathrm{yr}^{-1}$ and $14.1 \mathrm{~mm} \mathrm{yr}^{-1}$, with an average of $6.0 \mathrm{~mm} \mathrm{yr}^{-1}$.

The trends are not always spatially coherent and the values at some neighboring sites show large differences although the large uncertainty in the trend estimates does not make them statistically significant. For instance, Shijiusuo has a trend of $6.3 \pm 5.6 \mathrm{~mm} \mathrm{yr}^{-1}$ and Lianyungang which is about $100 \mathrm{~km}$ apart shows a trend of 14.1 $\pm 6.6 \mathrm{~mm} \mathrm{yr}^{-1}$. Thus these have a difference of $7.8 \mathrm{~mm} \mathrm{yr}^{-1}$ in the estimated trend although they cover the same period. This demonstrates the significant localization of changes in extremes.

The median ( $50^{\text {th }}$ percentile) values also show similar positive trends but with a lower rate ranging between $1.4 \mathrm{~mm} \mathrm{yr}^{-1}$ and $6.6 \mathrm{~mm} \mathrm{yr}^{-1}$ (Table 2). The subtraction of $50^{\text {th }}$ percentile from the $99.9^{\text {th }}$ percentile renders all rates statistically insignificant except at Shijiusuo, Lianyungang and Xiamen. 
The $\mathrm{M}_{2}$ tidal component also shows significant trends at 6 sites with the largest values at Shijiusuo $\left(4.5 \mathrm{~mm} \mathrm{yr}^{-1}\right)$, Lianyungang $(7.3 \mathrm{~mm} \mathrm{yr}-1)$ and Xiamen (4.6 $\mathrm{mm} \mathrm{yr}^{-1}$ ). The other three trends are statistically significant but smaller than 0.7 $\mathrm{mm}$ yr-1. Therefore it appears that the trends in the $99.9^{\text {th }}-50^{\text {th }}$ difference at Shijiusuo, Lianyungang and Xiamen are due to changes in the tidal amplitudes. We have performed a full analysis of tides for all stations that will be reported elsewhere. No other components show trends as strong as those found for $\mathrm{M}_{2}$ at these three stations.

It has been suggested that mean sea level rise could lead to the changes in tidal amplitudes and phases [Egbert et al., 2004; Jay, 2009; Green, 2010; Müller et al., 2011; Pickering et al., 2012]. Song et al. [2013] suggested, on the basis of modeling studies, that the extension of the coastal line due to reclamation could lead to the rise of the tidal amplitude. Since 1980s reclamation of tidal flat has been in the order of thousands of square kilometer [Li et al., 2004; Wang et al., 2011; Song et al., 2013]. We can not resolve on the basis of this dataset whether these changes in the tidal signal are caused by mean sea level changes or are due to anthropogenic or natural geomorphological changes or simply dredging operations near the tide gauges, but the changes are localized and of various strength thus suggesting probably local forcing.

When the TC-influenced data are removed the trends of sea level extremes do not change significantly - not a surprising result if their main cause is mean sea level rise. Note though that the trend on the $99.9^{\text {th }}-50^{\text {th }}$ difference at Shijusuo becomes insignificant and the trend at Shanwei becomes significant. 
The temporal changes in $99.9^{\text {th }}$ percentile of tidal residual are shown in Figure 7. There are no statistically significant trends except at Naha. The 50\% percentiles do show significant trends. Because the tidal residual extremes must be affected by mean sea level changes, it is rather surprising that none of the trends is significant. However the trends for the $99^{\text {th }}$ or $90^{\text {th }}$ percentiles are significant at most stations where the $50 \%$ percentiles have significant trends. Therefore, we believe that the lack of trends for the $99.9^{\text {th }}$ percentile of tidal residual is because of the large interannual variability that masks these trends.

\subsection{Interannual variability}

The interannual variation of $99.9^{\text {th }}$ percentile of sea level is larger at the mainland coasts, in particular at the coasts of the East China Sea (Figure 6). When the TC-influenced data are excluded the major features of the variability remain the same at most of the sites although the $99.9^{\text {th }}$ percentile and its standard deviation (STD) are both reduced as expected, by an average of $4.6 \mathrm{~cm}$ and $1.7 \mathrm{~cm}$ respectively.

For the tidal residuals when the TC-influenced data is excluded, the temporal patterns are greatly changed (Figure 7): correlations in pair of the two series are significant at only 8 sites. The extreme and its STD are reduced on average by $13.6 \mathrm{~cm}$ and $6.6 \mathrm{~cm}$ respectively demonstrating again the importance of tropical cyclones for extremes in the region.

The correlation between detrended $99.9^{\text {th }}$ percentile of sea level and detrended median sea level is positive and significant at 8 out of the 17 sites, generally in the north coasts, which are plotted in Figure 8a. Median sea level accounts for 7$49 \%$ of the variance in the extremes. At Dalian and Kaohsiung median sea level 
accounts for up to $49 \%$ and $43 \%$ of variance in the extremes respectively. At Haikou a negative correlation is found ( $r=-0.46)$ accounting for $30 \%$ of variance indicating that storminess behaves opposite to mean sea level at this station.

The extremes in tidal residual are correlated with the corresponding median values at only four stations, Dalian, Naha, Kaohsiung and Hongkong. After the removal of the TC-influenced data, in addition to these four stations, the correlations are significant at Keelung, Xiamen and Haikou.

Another factor that can influence the interannual variability of sea level extremes is the 18.6-year nodal modulation of the lunar tidal constitutes. The ratio $f$ between the nodal amplitude and its corresponding mean amplitude can be calculated using the equilibrium equation of nodal amplitude modulation [Pugh, 1996]:

$f=\alpha+\beta^{*} \cos (N)$

where $\alpha$ and $\beta$ are constant parameters that depend on tidal constituents, and $N$ is the longitude of the Moon's ascending node with a period of 18.6 years.

The nodal amplitudes computed by above equilibrium equation are significantly correlated with the detrended $99.9^{\text {th }}$ percentile of sea level at Dalian and 4 sites in the South China Sea. As a demonstration in figure 8b, the nodal cycle changes in $\mathrm{O}_{1}$ are shown. The nodal amplitude of $\mathrm{O}_{1}$ accounts for $16-75 \%$ of variance in the sea level extremes respectively. The nodal cycles for all tidal components will be discussed elsewhere.

Thirdly, the correlation of the Pacific Decadal Oscillation (PDO) index and the ENSO index with various percentiles of sea level and residual is also calculated. 
Note that the series of the PDO and ENSO indices are both obtained from National Climatic Data Center of NOAA. The PDO is significantly correlated with percentiles at $50^{\text {th }} \sim 80^{\text {th }}$ but not with the $99.9^{\text {th }}$ percentile, at Lianyungang, Kanmen, Kaohsiung and Shanwei. The ENSO is found to be correlated with the $50^{\text {th }} \sim 80^{\text {th }}$ percentiles at Xiamen, Hongkong, Zhapo and Haikou, i.e. the more southern coasts. When the TC-influenced data are removed the correlations between the two indices and the various percentiles are not significantly changed. In conclusion neither the PDO nor ENSO are good descriptors of the size of extremes.

Fourthly, the interannual number of TC-influenced events in the whole area of study is further detected (shown by the blue line in Figure 9). The period of analysis is restricted to $1975-1997$ when most stations have values. An increasing during the period can visually be detected but is not statistically significant. We also find the total number of tropical cyclones in the NW Pacific, based on the RSMC Tokyo of JMA dataset, to increase with a rate of $0.27 \pm 0.22$ times $\mathrm{yr}^{-1}$, which has been linked to the increase of sea surface temperature in the Main Development Region [Emanuel, 2005]. The annual number of tropical cyclones does not correlate with ENSO $(r=-0.02)$. However the number of TCinfluenced events in sea level (detrended) is significantly correlated with the ENSO at 93\% confidence level $(r=-0.39)$. Similarly the ratio of the number of TCinfluenced events in the Chinese coasts over the total number of tropical cyclones in the NW Pacific (red line in Figure 9) has a significant correlation with the ENSO at $92 \%$ confidence level $(r=-0.37)$. We also confirm that the South China Sea is the region that dominates the correlation with ENSO (now shown here). 
This means that the difference between El Niño and La Niña years does not concern the number of tropical cyclones generated but the paths they follow. During La Niña years more tropical cyclones get to the Chinese coasts while less do so during El Niño. Wu and Wang [2005] showed that the paths of tropical cyclones during El Nino years are oriented further to the north in agreement with what our results suggest.

\section{The influence of global mean temperature on regionally TC-}

\section{influenced extremes in tidal residuals}

Grinsted et al. [2013] found that the changes in global mean temperature correlate with the storm surges caused by the strongest tropical cyclones in the NW Atlantic. We look for a similar effect for the NW Pacific by developing extremal indices for three areas: first the Bohai Sea and Yellow Sea, second the East China Sea and third the South China Sea. We also develop an extremal index for the whole area.

For each area an extremal index based on the regional average and one based on the regional maxima is developed. The extremal indices are calculated using the values of TC-influenced events over the annual largest 10 events at each site of the four regions. The period of analysis is $1975-1997$ when most stations have observational data.

None of the two indices calculated for tidal residual in the three regions and whole area show significant trends. Thus there is no correspondence between increases in global temperature, which shows a significant trend, and the size of the extremes. Thus the result of Grinsted et al. [2013] for the Atlantic coasts in relation to the trends does not apply for the Chinese coasts. 
The correlation of detrended global temperature time series ( $\left.\mathrm{T}_{\mathrm{GLOB}}\right)$ with the index of regional average $\left(\mathrm{EI}_{\mathrm{REG}_{-} \mathrm{AVG}}\right)$, which is closer to the index used by Grinstead et al. [2013] than the regional maxima (EI REG_MAX $_{\text {, }}$, is not statistically significant. The linear regression, $\mathrm{EI}_{\mathrm{REG}_{\_} \mathrm{AVG}}$ or REG_MAX $=a \mathrm{~T}_{\mathrm{GLOB}}+b$, was performed where $a$ is the regression coefficient and $b$ the regression constant. The index of regional maxima at the South China Sea and for the whole region shows statistically significant correlation ( $r=0.44$ and 0.43 respectively), with a regression coefficient of $1.00 \pm 0.91 \mathrm{~m} \mathrm{C}^{\circ}-1$ and $1.45 \pm 1.3 \mathrm{~m} \mathrm{C}^{\circ}-1$ respectively (Figure 10). The two other areas do not show significant correlations either at the extremal index of regional average or the regional maxima.

The data for the La Niña years of 1975 and 1988 are not outliers. However when these are removed from the series, the correlations of the index of regional average for the South China Sea and the whole area both become significant with $r=0.54$ and 0.45 , and the correlation of the index of regional maxima is further improved to $r=0.47$ and 0.61 respectively. The regression coefficients are $0.26 \pm 0.19$ and $0.26 \pm 0.25 \mathrm{~m} \mathrm{C}^{-1}$ for the index of regional average in the South China Sea and whole area, and $1.13 \pm 1.02$ and $1.72 \pm 1.09 \mathrm{~m} \mathrm{C}^{\circ}-1$ for the index of regional maxima respectively. The above also shows that the correlation of the region with the global temperature is explained by the dominance of the effects of the South China Sea.

We have already shown that the number of tropical cyclones reaching the Chinese coast, in particular at the South China Sea latitude, depends on ENSO but does not affect the size of the extremes. However the interannual variability of global temperature is a better descriptor of extremes than ENSO. The reason why 
this is the case is not clear, as it was not in Grinsted et al. [2013]. In the present study there is no correspondence of the trend in global temperature as there is no trend in the tidal residual maxima. There is a hint of increase on the number of cyclones reaching the coast but it is not statistically significant. Thus the obtained scaling for the interannual variability of extremal indices of tidal residual with global temperature can be speculated to be caused by changes in the tracks of tropical cyclones rather than their strength, so that the areas where correlation exist comes in and out of the focus of tropical cyclones depend on the global temperature. It can further be speculated that during La Niña years when the warm water pool in the Pacific is located closest to the Chinese coasts, the changes in global temperature do not matter so much in determining the tropical cyclone tracks. However the issue is not resolved and we could not rule out the possibility that global temperature does affect the size of extremes but the interannual variability is so strong that the trend is not detectable yet. Note that we repeated the same analysis for Hongkong which has a long sea level record of 51 years and there is no evidence of trend in extremes of TC-influenced residuals for this longer period either.

\section{Conclusion and discussion}

The spatial distribution and the long-term changes of sea level and tidal residual extremes in the Chinese seas have been mapped. The sea level maxima are dominated by the tidal amplitudes combined with the effect of tropical cyclones. The tidal residual maxima are dominated by the presence of tropical cyclones. The 50-year return levels of sea level and tidal residual have also been estimated 
using variable number of extreme values. The stability of the estimation depends on whether the extremes used for the estimation come solely from tropical cyclones or by local strong storms.

Long-term trends were found for the $99.9^{\text {th }}$ percentile of sea level at 12 sites. The average trend is $6.0 \mathrm{~mm} \mathrm{yr}^{-1}$, with a range of $2.0-14.1 \mathrm{~mm} \mathrm{yr}^{-1}$. The trends are mainly driven by changes in the median sea level. However at three stations of Shijiusuo, Lianyungang and Xiamen they are additionally caused by changes in the tidal amplitudes. No significant trends were found in the $99.9^{\text {th }}$ percentile of tidal residual because of the disturbing of interannual variability.

Significant interannual variability was found in the sea level extremes. Part of it is caused by variations in tropical cyclones. At the northern tide gauges the intreannual variability is more dominated by changes in the median values. However, in the South China Sea the variability is mainly dominated by the 18.6year nodal cycle. The nodal modulation of $\mathrm{O}_{1}$ can explain $37-75 \%$ of variability. The interannual variability of tidal residual is predominantly caused by the tropical cyclones.

Han and Huang [2008] based on altimetry data indicated the interannual variability of mean sea level in the north Chinese coasts over 1992-2002 can be due to the phase change of the PDO. However, we did not found such a relationship in either the $50^{\text {th }}$ percentile or the $99.9^{\text {th }}$ percentile over the period we studies. The exception is Lianyungang, where the $50 \%$ percentile is correlated with the PDO. The ENSO seems to be an indicator of sea level at moderate-to-high percentiles, but not for extremes. It is also found that the ENSO 
regulates the number of tropical cyclones that reach the Chinese coasts and in particular the coasts of the South China Sea.

Global mean atmospheric temperature plays a role in the determination of the interannual variability of tidal residual extremes caused by tropical cyclones but not in the trends. This influence is restricted to the South China Sea and is not evident in the northern regions of the area of study. It also becomes more evident when the two La Niña events contained in the records are excluded from the analysis.

In conclusion, the long-term changes of sea level extremes in the area of study depend on mean sea level changes, as well as changes in the tidal amplitudes. The extreme events are primarily caused by tropical cyclones. Projections for the future require skills in assessing the strengthening or weakening of tropical cyclones in the area, changes in their paths as well as the modification of the tidal signal. We plan to synthesise the results of this study with mean sea level and predictions for changes in the tidal signal to assess the future extremes in the area.

\section{Acknowledgements}

This research is funded by Lloyd's Register Foundation, which supports the advancement of engineering-related education, and funds research and development that enhances safety of life at sea, on land and in the air, and also supported by National Natural Science Foundation of China (Grant No. 51109075). We also acknowledge Dr. M.G.G Foreman for making his tidal analysis and prediction programs publically available. 


\section{References:}

Cai, F., X. Su, J. Liu, B. Li, and G. Lei (2009), Coastal erosion in China under the condition of global climate change and measures for its prevention, Progress in Natural Science, 19(4), 415-426.

Cartwright, N., L. Li, and P. Nielsen (2004), Response of the salt-freshwater interface in a coastal aquifer to a wave-induced groundwater pulse: field observations and modelling, Advances in Water Resources, 27(3), 297-303.

Chan, J. C. L. (2006), Comment on "Changes in Tropical Cyclone Number, Duration, and Intensity in a Warming Environment", Science, 311, 1713.

Chan, J.C.L., and K.S. Liu (2004), Global warming and Western North Pacific typhoon activity from an observational perspective, Journal of Climate, 17, 4590-4602.

Coles, S. (2001), An introduction to statistical modeling of extreme values, London: Springer.

Ding, X., D. Zheng, Y. Chen, J. Chao, and Z. Li (2001), Sea level change in Hong Kong from tide gauge measurements of 1954-1999, Journal of Geodesy, 74(10), 683-689.

Doong, D. J., T. W. Hsu, L. C. Wu, and C. C. Kao (2009), Sea level rise at East Asia coasts based on tide gauge analysis, In Proceedings of the Nineteenth International Offshore and Polar Engineering Conference (ISOPE 2009), 513-517.

Du, Y., L. Yang, and S. P. Xie (2011), Tropical Indian Ocean Influence on Northwest Pacific Tropical Cyclones in Summer following Strong El Niño. Journal of climate, 24, 315-322.

Egbert, G. D., R. D. Ray, and B. G. Bills (2004), Numerical modeling of the global semidiurnal tide in the present day and in the last glacial maximum, Journal of Geophysical Research, 109, C03003, doi: DOI: 10.1029/2003JC001973

Emanuel, K. (2005), Increasing destructiveness of tropical cyclones over the past 30 years, Nature, 436, 686-688.

Fan, D., and C. Li (2006), Complexities of China's coast in response to climate change, Advances in Climate Change Research, 2(Suppl 1), 54-58.

Fan, D., Y. Guo, P. Wang, and J. Z. Shi (2006), Cross-shore variations in morphodynamic processes of an open-coast mudflat in the Changjiang Delta, China: with an emphasis on storm impacts, Continental Shelf Research, 26(4), 517-538.

Frank, W. M. (1977), The structure and energetics of the tropical cyclone I. Storm structure, Monthly Weather Review, 105(9), 1119-1135.

Gratiot, N., E. J. Anthony, A. Gardel, C. Gaucherel, C. Proisy, and J. T. Wells (2008), Significant contribution of the 18.6 year tidal cycle to regional coastal changes, Nature Geoscience, 1(3), 169-172. 
Gray, W.M. (1984), Atlantic seasonal hurricane frequency: Part I: El Niño and 30-mb quasi-biennial oscillation influences, Monthly Weather Review, 112, 1649-1668.

Green, J. A. M. (2010), Ocean tides and resonance, Ocean Dynamics, 60(5), 1243-1253.

Grinsted, A., J. C. Moore, and S. Jevrejeva (2013), Projected Atlantic hurricane surge threat from rising temperatures, Proceedings of the National Academy of Sciences, 110(14), 5369-5373.

Haigh, I, R. Nicholls, and N. Wells (2010), Assessing changes in extreme sea levels: application to the English Channel, 1900-2006, Continental Shelf Research, 30(9), 1042-1055.

Hallegatte, S., C. Green, R. J. Nicholls, and J. Corfee-Morlot (2013), Future flood losses in major coastal cities, Nature Climate Change, 3, 802806.

Han, G., and W. Huang (2008), Pacific decadal oscillation and sea level variability in the Bohai, Yellow, and East China seas, Journal of Physical Oceanography, 38(12), 2772-2783.

Jay, D. A. (2009), Evolution of tidal amplitudes in the eastern Pacific Ocean, Geophysical Research Letters, 36(4), L04603.

Kim, H. M., P. J. Webster, and J. A. Curry (2011), Modulation of North Pacific Tropical Cyclone Activity by Three Phases of ENSO. Journal of climate, 24, 1839-1849.

Knutson, T. R., J. L. McBride, J. Chan, K. Emanuel, G. Holland, C. Landsea, I. Held, et al. (2010), Tropical cyclones and climate change, Nature Geoscience, 3(3), 157-163.

Kuleshov, Y., and G. de Hoedt (2003), Tropical cyclone activity in the Southern Hemisphere, Bulletin of the Australian Meteorological and Oceanographic Society, 16, 135-137.

Kuleshov, Y., L. Qi, R. Fawcett, and D. Jones (2008), On tropical cyclone activity in the Southern Hemisphere: Trends and the ENSO connection, Geophysical Research Letters, 35, L14S08.

Kuleshov, Y., R. Fawcett, L. Qi, B. Trewin, D. Jones, J. McBride, and H. Ramsay (2010), Trends in tropical cyclones in the South Indian Ocean and the South Pacific Ocean, Journal of Geophysical Research: Atmospheres (1984-2012), 115, D01101, doi:10.1029/2009JD012372.

Lander, M. (1994), An exploratory analysis of the relationship between tropical storm formation in the Western North Pacific and ENSO, Monthly Weather Review, 122, 636-651.

Landsea, C. W., B. A. Harper, K. Hoarau, and J. A. Knaff (2006), Can we detect trends in extreme tropical cyclones, Science, 313, 452-454.

Lau, M. A. (2006), Adaptation to sea-level rise in the People's Republic of China-assessing the institutional dimension of alternative organisational frameworks (No. FNU-94).

Li, C., D. Fan, B. Deng, and V. Korotaev (2004), The coasts of China and issues of sea level rise, Journal of Coastal Research, SI 43, 36-49.

Mackey, B. P., and T. N. Krishnamurti (2001), Ensemble forecast of a typhoon flood event, Weather and Forecasting, 16(4), 399-415. 
Marcos, M., M. N. Tsimplis, and A. G. Shaw (2009), Sea level extremes in southern Europe, Journal of

Geophysical Research, 114, C01007.

Marcos, M., M. N. Tsimplis, F. M. Calafat (2012), Inter-annual and decadal sea level variations in the north-western Pacific marginal seas, Progress in Oceanography, 105, 4-21.

Menéndez, M., and P. L. Woodworth (2010), Changes in extreme high water levels based on a quasiglobal tide-gauge data set, Journal of Geophysical Research, 115, C10011.

Moon, I., I. Oh, T. Murty, and Y. Youn (2003), Causes of the unusual coastal flooding generated by Typhoon Winnie on the west coast of Korea, Natural Hazards, 29, 485-500.

Müller, M., B. K. Arbic, and J. X. Mitrovica (2011), Secular trends in ocean tides: observations and model results, Journal of Geophysical Research, 116, C05013.

Murakami, H., Y. Wang, H. Yoshimura, R. Mizuta, M. Sugi, E. Shindo, and A. Kitoh (2012), Future changes in tropical cyclone activity projected by the new high-resolution MRI-AGCM, Journal of Climate, 25(9), 3237-3260.

Palutikof, J. P., B. B. Brabson, D. H. Lister, and S. T. Adcock (1999), A review of methods to calculate extreme wind speeds, Meteorological Applications, 6(2), 119-132.

Pickering, M. D., N. C. Wells, K. J. Horsburgh, and J. A. M. Green (2012), The impact of future sealevel rise on the European Shelf tides, Continental Shelf Research, 35, 1-15.

Pugh, D.T., (1996), Tides, surges and mean sea-level (reprinted with corrections), John Wiley and Sons Ltd, Chichester, UK 486 pp.

Shaw, A. G. P., and M. N. Tsimplis (2010), The $18.6 \mathrm{yr}$ nodal modulation in the tides of southern European coasts, Continental Shelf Research, 30(2), 138-151.

Smith, R. L. (1989), Extreme value analysis of environmental time series: an application to trend detection in ground-level ozone, Statistical Science, 4(4), 367-377.

Song, D., X. Wang, X. Zhu, and X. Bao (2013), Modeling studies of the far-field effects of tidal flat reclamation on tidal dynamics in the East China Seas, Estuarine, Coastal and Shelf Science, 133, $147-160$.

State Oceanic Administration (SOA) (2013a), China Ocean Disasters Bulletin in 2012, Beijing, China. (in Chinese)

State Oceanic Administration (SOA) (2013b), Report of Sea Level Rise at Chinese Coast in 2012, Beijing, China. (in Chinese)

Torres, R. R., and M. N. Tsimplis (2011), Tides and long-term modulations in the Caribbean Sea, Journal of Geophysical Research, 116, C10022.

Torres, R. R., and M. N. Tsimplis (2012), Seasonal sea level cycle in the Caribbean Sea, Journal of Geophysical Research, 117, (C7), C07011. 
Trenberth, K. E., and J. Fasullo (2007), Water and energy budgets of hurricanes and implications for

climate change, Journal of Geophysical Research, 112, D23107.

Trenberth, K. E., C. A.,Davis, and J. Fasullo (2007), Water and energy budgets of hurricanes: Case studies of Ivan and Katrina, Journal of Geophysical Research, 112, D23106.

Tsimplis, M. N., and A.G.P. Shaw (2010), Seasonal sea level extremes in the Mediterranean Sea and at the Atlantic European coasts, Natural Hazards and Earth System Sciences, 10 (7). 1457-1475.

Tsimplis, M. N., and D. Blackman (1997), Extreme sea-level distribution and return periods in the Aegean and Ionian Seas, Estuarine, Coastal and Shelf Science, 44(1), 79-89.

Wang, X.H., F. Qiao, J. Lu, F. Gong (2011), The turbidity maxima of the northern Jiangsu shoal-water in the Yellow Sea, China, Estuarine, Coastal and Shelf Science, 93 (3), 202-211.

Webster, P. J., J. A. Curry, J. Liu, and G. J. Holland (2005), Changes in tropical cyclone number, duration and intensity in a warming environment, Science, 309, 1844-1846.

Webster, P. J., J. A. Curry, J. Liu, and G. J. Holland (2006), Response to comment on "Changes in tropical cyclone number, duration, and intensity in a warming environment", Science, 311, 1713.

Woodworth, P. L., and D. L. Blackman (2004), Evidence for systematic changes in extreme high waters since the mid-1970s, Journal of Climate, 17(6), 1190-1197.

Wu, C. C., T. H. Yen, Y. H. Kuo, and W. Wang (2002), Rainfall simulation associated with Typhoon Herb (1996) near Taiwan - Part I: the topographic effect, Weather and Forecasting, 17(5), 10011015 .

Wu, L., and B. Wang (2004), Assessing Impacts of global warming on tropical cyclone tracks, Journal of climate, 17(8), 1686-1698.

Yanagi, T., and T. Akaki (1994), Sea level variation in the Eastern Asia, Journal of Oceanography, $50(6), 643-651$.

Yang, S. L., C. T. Friedrichs, Z. Shi, P. X. Ding, J. Zhu, and Q. Y. Zhao (2003), Morphological response of tidal marshes, flats and channels of the outer Yangtze River mouth to a major storm, Estuaries, 26(6), 1416-1425.

Yin, B., Z. Xu, Y. Huang, and X. Lin (2009), Simulating a typhoon storm surge in the East Sea of China using a coupled model, Progress in Natural Science, 19(1), 65-71.

Zhang, W. Z., F. Shi, H. S. Hong, S. P. Shang, and J. T. Kirby (2010), Tide-surge Interaction Intensified by the Taiwan Strait, Journal of Geophysical Research, 115, C06012.

Zhang, W., Y. Yan, J. Zheng, L. Li, X. Dong, and H. Cai (2009), Temporal and spatial variability of annual extreme water level in the Pearl River Delta region, China, Global and Planetary Change, 69(1), 35-47. 
Zhou, X., J. Zheng, D. J. Doong, and Z. Demirbilek (2013), Sea level rise along the East Asia and Chinese coasts and its role on the morphodynamic response of the Yangtze River Estuary, Ocean Engineering, 71, 40-50.

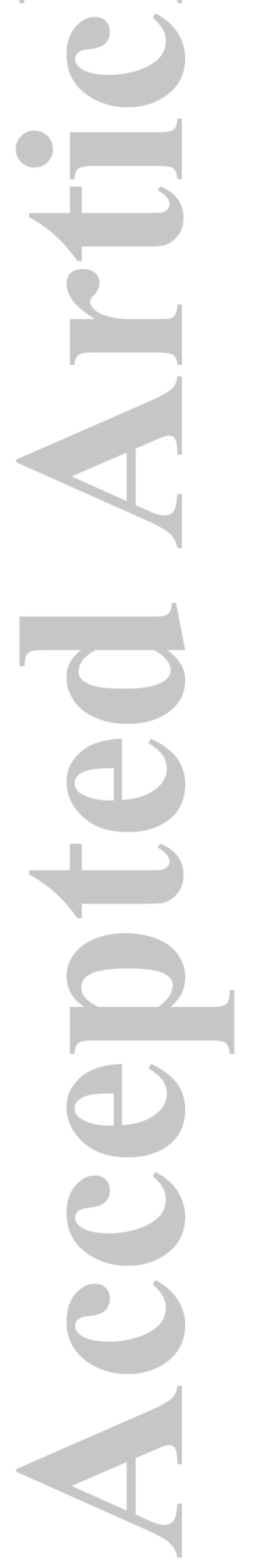



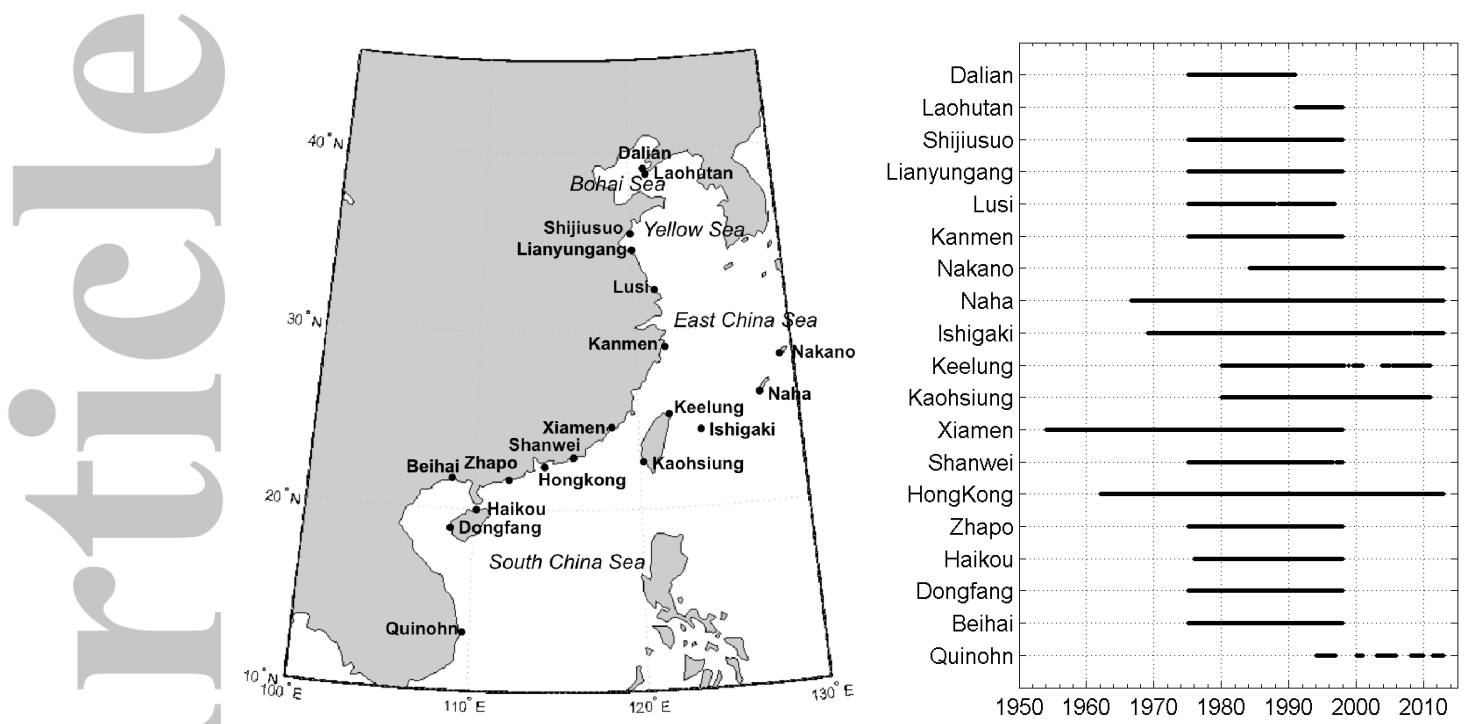

Figure 1. Location of tide gauges and quality-controlled data during 1954-2012.

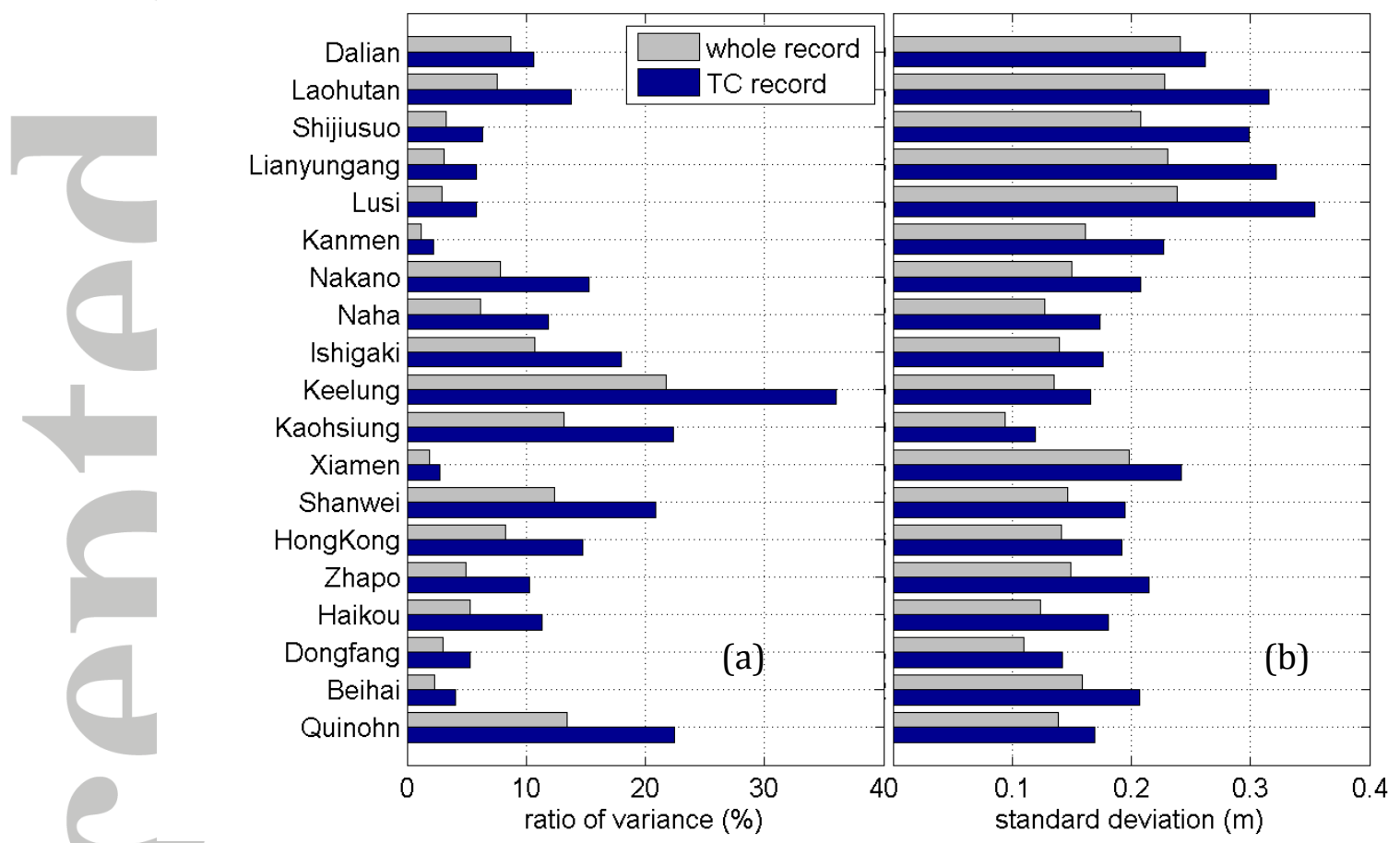

Figure 2. The ratio of variance of tidal residual over the variance of sea level (a) and the standard deviation of tidal residual (b), for the whole record (grey) and for only the TC-influenced record (blue). 


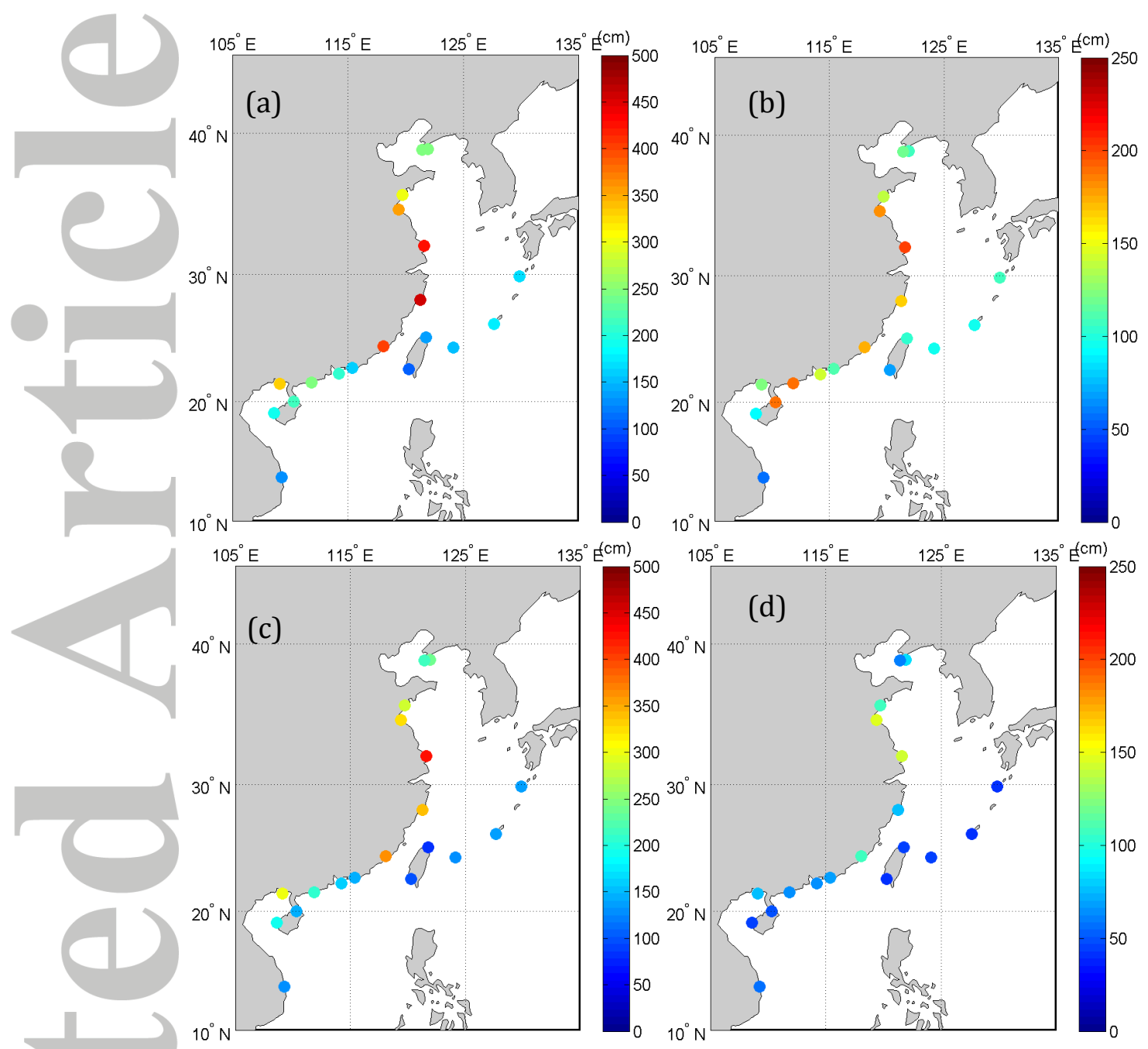

Figure 3. Maximum observed sea level (a, c) and tidal residual (b, d) when tropical cyclones are taken $(a, b)$ and not taken into account $(c, d)$.

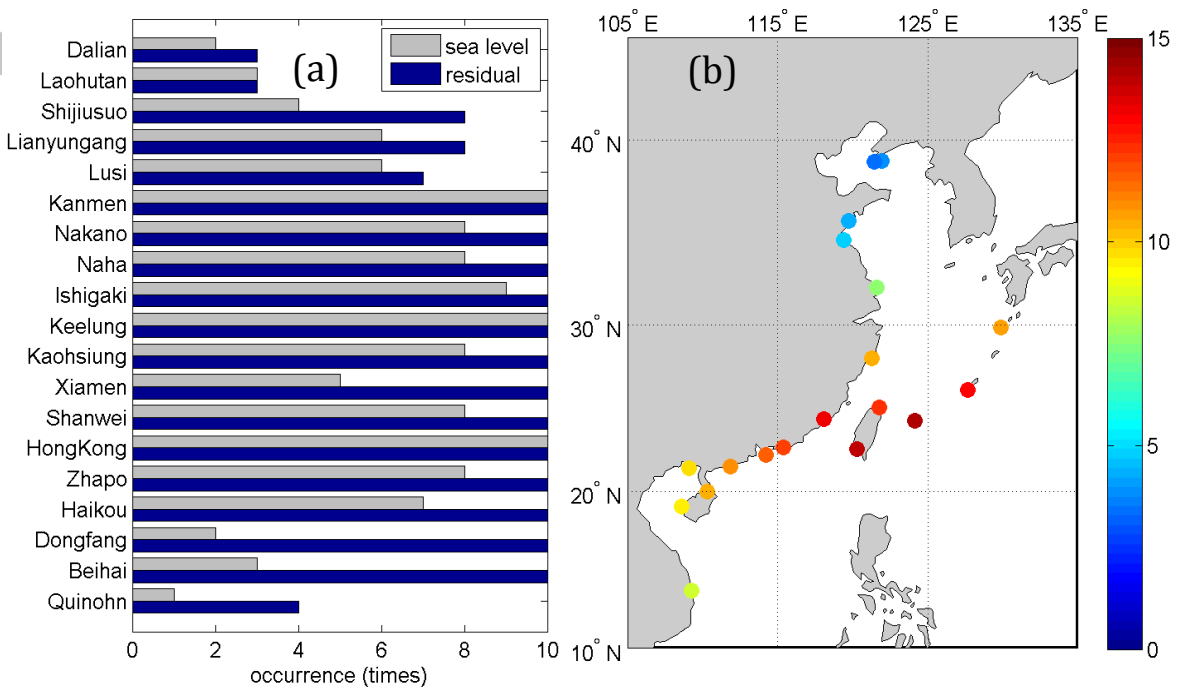

Figure 4. (a) Number of TC-influenced events with respect to the largest 10 events over the whole observational period, and (b) annual number of TCinfluenced events (times). 

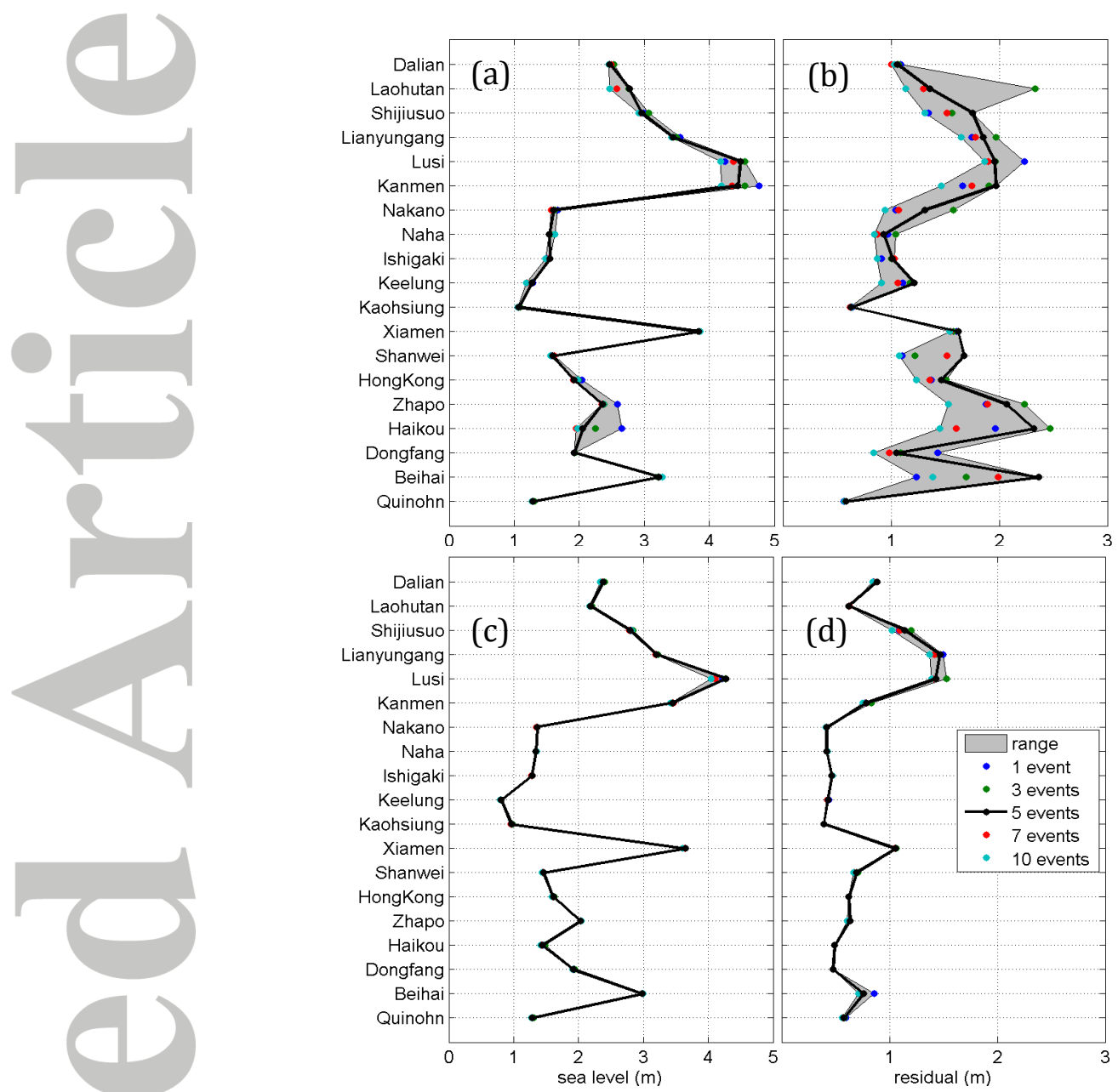

Figure 5. 50-year return levels of sea level $(a, c)$ and tidal residual $(b, d)$ estimated by GPD with different number of events per year when tropical cyclones are taken $(a, b)$ and not taken (c, d) into account.
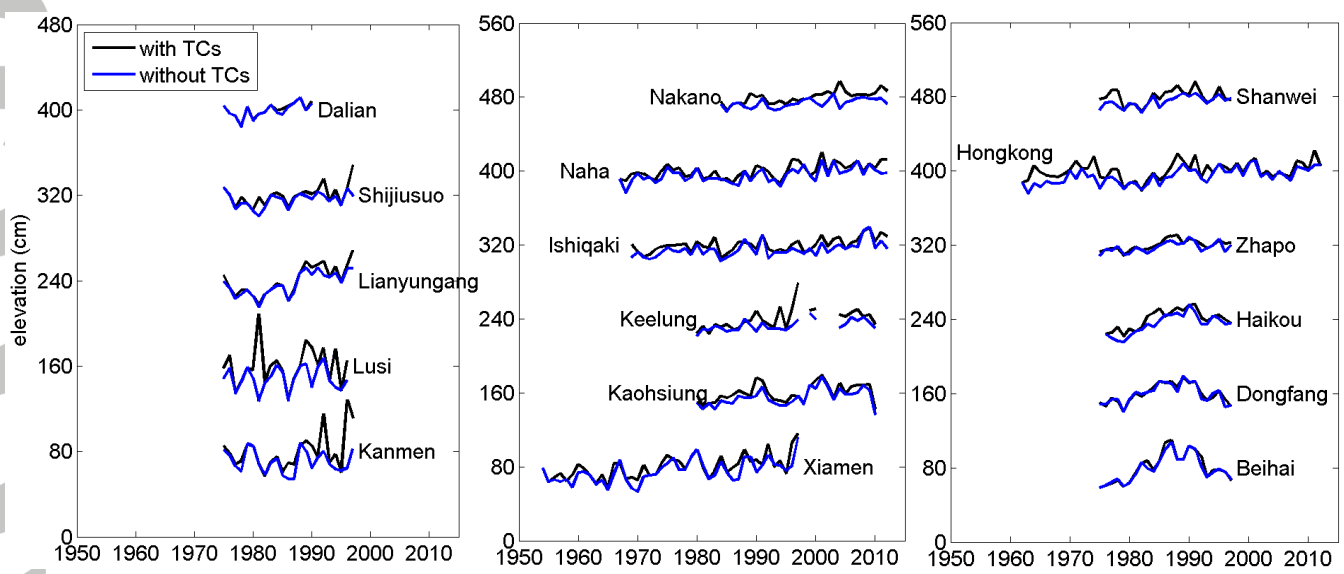

Figure 6. Annual values of $99.9^{\text {th }}$ percentile of sea level when tropical cyclones are taken (black lines) and not taken (blue lines) into account. 


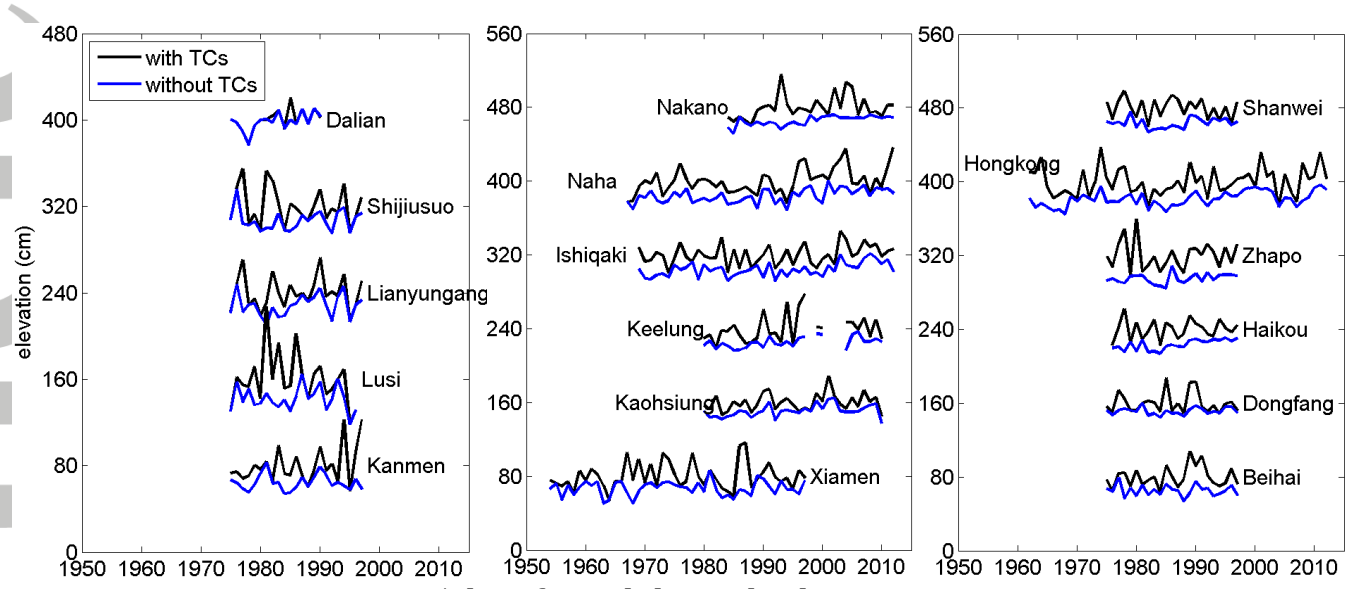

Figure 7. Same as Figure 5, but for tidal residual.
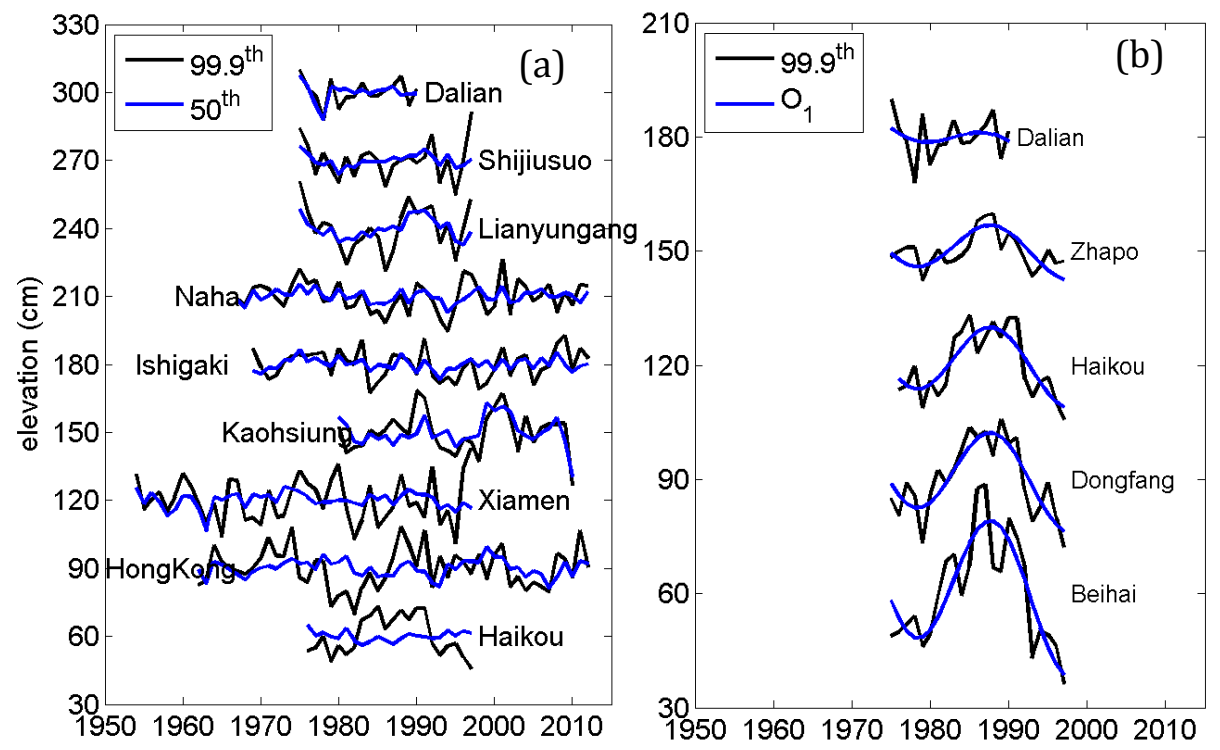

Figure 8. (a) Detrended time series of $99.9^{\text {th }}$ and $50^{\text {th }}$ percentiles of sea level, and (b) detrended time series of $99.9^{\text {th }}$ percentile of sea level and 18.6-year nodal cycle of $\mathrm{O}_{1}$. 


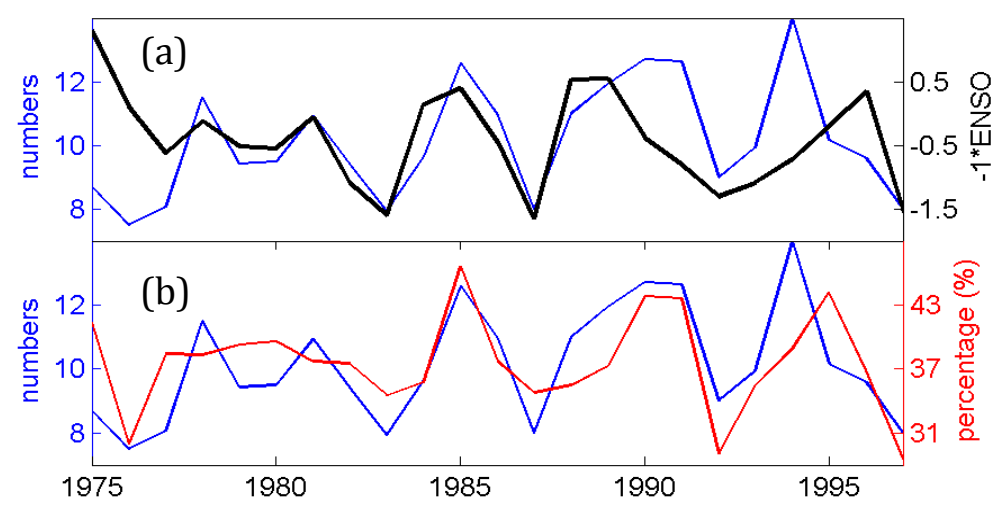

Figure 9. (a) Number of TC-influenced events per year (blue line) in the area of study and the corresponding inverted ENSO index (black line), and (b) the number of TC-influenced events per year together with the percentage of tropical cyclones generated in the NW Pacific that reach the Chinese coasts (red line) over 1975-1997.

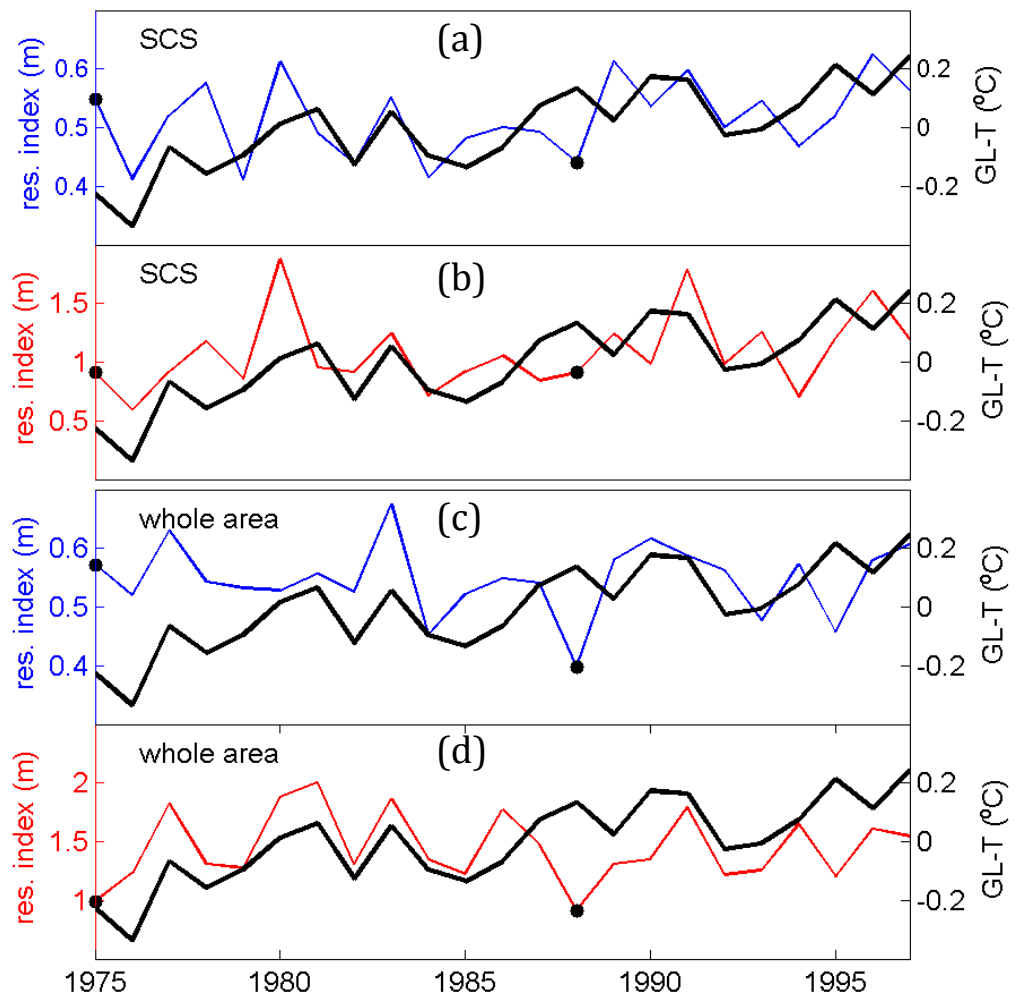

Figure 10. Time series of extremal indices (blue lines for regional average and red for regional maxima) against global mean temperature anomaly (black lines) in the South China Sea (a, b) and the whole area of study (c, d) over 1975-1997. Black dots indicate the values of index in the strong La Niña years. Note that all the time series are not detrended in the plots. 


\section{Tables}

Table 1. The Chi-squared tests of top five residual events (per year) distributed along the tidal phase (the highlighted are the cases that are significantly different from normal distribution at 99\% confidence levels)

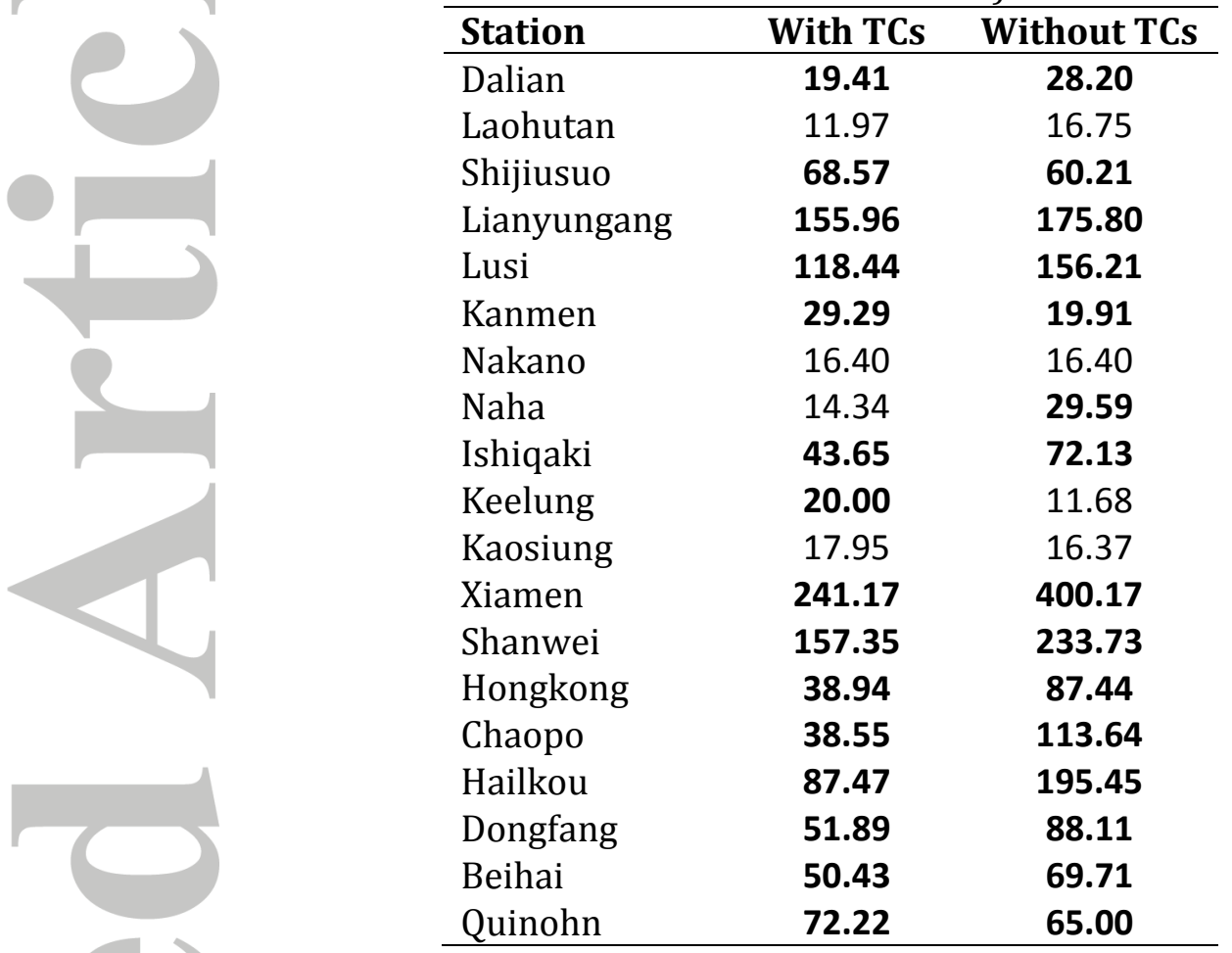

Table 2. Linear trends of sea level percentiles and $\mathrm{M}_{2}$ over observational periods $\left(\mathrm{cm} \mathrm{yr}^{-1}\right)$. The errors are at the $95 \%$ confidence level. Those trends statistically significant at the 95\% confidence level have been highlighted.

\begin{tabular}{lcccc}
\hline Station & $\mathbf{9 9 . 9}^{\text {th }}$ & $\mathbf{5 0}^{\text {th }}$ & $\mathbf{9 9 . 9}^{\text {th }}-\mathbf{5 0 ^ { \text { th } }}$ & $\mathbf{M}_{\mathbf{2}}$ \\
\hline Dalian & $\mathbf{0 . 8 3} \pm \mathbf{0 . 6 7}$ & $\mathbf{0 . 6 6} \pm \mathbf{0 . 5 0}$ & $0.17 \pm 0.48$ & $-0.02 \pm 0.20$ \\
Shijiusuo & $\mathbf{0 . 6 3} \pm \mathbf{0 . 5 6}$ & $\mathbf{0 . 0 8} \pm \mathbf{0 . 1 9}$ & $\mathbf{0 . 5 5} \pm \mathbf{0 . 4 8}$ & $\mathbf{0 . 4 5} \pm \mathbf{0 . 0 7}$ \\
Lianyungang & $\mathbf{1 . 4 1} \pm \mathbf{0 . 6 6}$ & $\mathbf{0 . 4 6} \pm \mathbf{0 . 3 1}$ & $\mathbf{0 . 9 5} \pm \mathbf{0 . 5 2}$ & $\mathbf{0 . 7 3} \pm \mathbf{0 . 1 0}$ \\
Lusi & $0.25 \pm 1.30$ & $\mathbf{0 . 3 5} \pm \mathbf{0 . 2 1}$ & $-0.11 \pm 1.2$ & $0.06 \pm 0.06$ \\
Kanmen & $1.05 \pm 1.09$ & $0.09 \pm 0.15$ & $0.96 \pm 1.06$ & $0.07 \pm 0.08$ \\
Nakano & $\mathbf{0 . 5 6} \pm \mathbf{0 . 2 1}$ & $\mathbf{0 . 3 9} \pm \mathbf{0 . 1 0}$ & $0.17 \pm 0.21$ & $-0.02 \pm 0.02$ \\
Naha* $^{*}$ & $\mathbf{0 . 3 3} \pm \mathbf{0 . 1 5}$ & $\mathbf{0 . 2 3} \pm \mathbf{0 . 0 6}$ & $0.10 \pm 0.12$ & $0.00 \pm 0.01$ \\
Ishiqaki $^{*}$ & $\mathbf{0 . 3 1} \pm \mathbf{0 . 1 5}$ & $\mathbf{0 . 2 8} \pm \mathbf{0 . 0 6}$ & $0.03 \pm 0.13$ & $0.01 \pm 0.01$ \\
Keelung & $\mathbf{0 . 8 0} \pm \mathbf{0 . 5 1}$ & $\mathbf{0 . 5 1} \pm \mathbf{0 . 2 1}$ & $0.29 \pm 0.48$ & $\mathbf{0 . 0 7} \pm \mathbf{0 . 0 2}$ \\
Kaosiung & $\mathbf{0 . 3 9} \pm \mathbf{0 . 3 7}$ & $\mathbf{0 . 3 5} \pm \mathbf{0 . 2 7}$ & $0.04 \pm 0.28$ & $\mathbf{0 . 0 3} \pm \mathbf{0 . 0 2}$ \\
Xiamen & $\mathbf{0 . 6 0} \pm \mathbf{0 . 2 4}$ & $\mathbf{0 . 1 4} \pm \mathbf{0 . 0 9}$ & $\mathbf{0 . 4 6} \pm \mathbf{0 . 2 3}$ & $\mathbf{0 . 1 5} \pm \mathbf{0 . 0 4}$ \\
Shanwei & $0.32 \pm 0.53$ & $0.08 \pm 0.13$ & $0.24 \pm 0.54$ & $-0.02 \pm 0.02$ \\
Hongkong* & $\mathbf{0 . 2 0} \pm \mathbf{0 . 1 7}$ & $\mathbf{0 . 2 7} \pm \mathbf{0 . 0 7}$ & $-0.07 \pm 0.16$ & $\mathbf{- 0 . 0 4} \pm \mathbf{0 . 0 2}$ \\
Chaopo & $\mathbf{0 . 5 1} \pm \mathbf{0 . 3 0}$ & $\mathbf{0 . 1 7} \pm \mathbf{0 . 1 5}$ & $0.34 \pm 0.35$ & $-0.02 \pm 0.03$ \\
Hailkou & $\mathbf{0 . 9 4} \pm \mathbf{0 . 6 2}$ & $\mathbf{0 . 6 8} \pm \mathbf{0 . 1 6}$ & $0.26 \pm 0.71$ & $0.02 \pm 0.09$ \\
Dongfang & $0.44 \pm 0.65$ & $0.08 \pm 0.11$ & $0.36 \pm 0.68$ & $0.02 \pm 0.04$ \\
Beihai & $\mathbf{0 . 9 3} \pm 0.95$ & $0.12 \pm 0.14$ & $0.81 \pm 0.96$ & $0.05 \pm 0.15$ \\
\hline
\end{tabular}




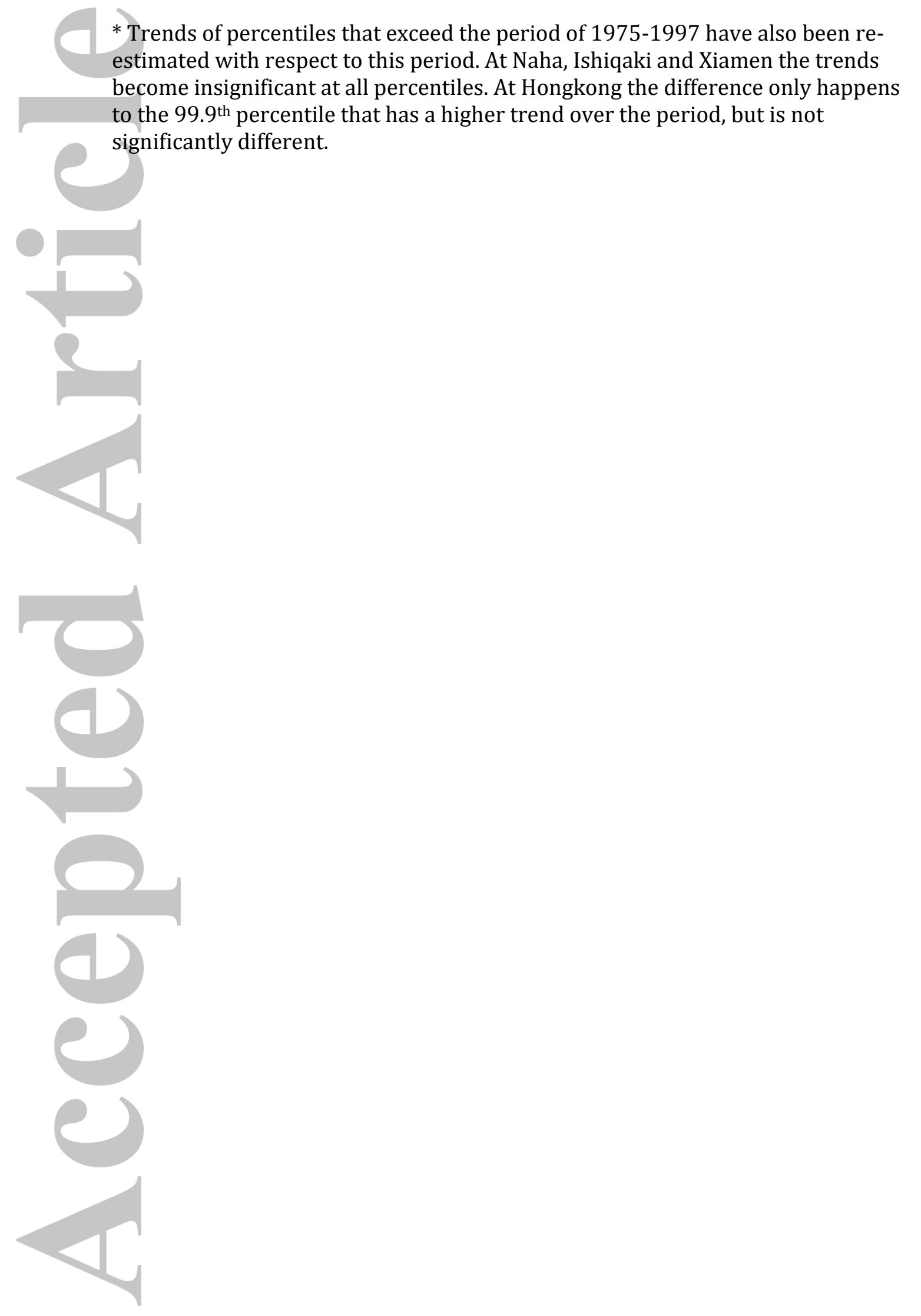

